\title{
PRIMARY TUBERCULOUS INFECTION IN CHILDHOOD INCIDENCE, MORBIDITY, AND MORTALITY IN AN URBAN POPULATION
}

\author{
BY
}

\author{
BRIAN C. THOMPSON, M.D. \\ (From the Ealing Chest Clinic, London)
}

It is universally recognized that tuberculin skin tests done on a mass scale can afford epidemiological information of great value in an antituberculosis campaign. In many countries extensive and repeated surveys have been made during the past twenty-five years in various population samples. It has been conclusively shown, for instance (Myers, 1944), that in the United States tuberculous infection has become measurably less frequent and has become postponed to a later age-this change taking place to a degree greater in some communities than in others. In Great Britain, no comparable studies are available. Tuberculin testing of children has been limited to hospital patients (Schlesinger and Hart, 1930; Dow and Lloyd, 1931; Bradshaw, 1939); and the only large-scale work on unselected children is that of Jones Davies (1943) in a Welsh rural area, and of Heimann and Paterson (1945) in Bournemouth.

\section{Tuberculin Sensitivity}

During the years $1942-45$, inclusive, 1,476 children below the age of 14 made an initial attendance at the Ealing Chest Clinic. Of these, 1,050 came primarily without symptoms, as contacts of known cases of tuberculosis. The remaining 426 were referred by general medical practitioners or medical officers to the school or infant welfare clinics on account of specific symptoms. The former 1,050 we designated 'contacts,' the latter 426 'noncontacts.'

Our routine technique of tuberculin testing was as follows. A visiting nurse applied a tuberculin patch (Vollmer type) at the patient's home three days before his appointment at the clinic, with instructions for it to be removed forty-eight hours later. The test was read at the time of attendance, and, if negative, was followed by an intradermal (Mantoux) injection of $\cdot 01 \mathrm{c.cm}$. of tuberculin-purified protein derivative, second strength, or of $1 / 100$ old tuberculin during a period when the former was unobtainable. That such a relatively strong dose was justified is shown by the high percentage of positive reactors it revealed in children negative to the patch test. At the same time, the almost complete absence of severe reactions from the intradermal test has satisfied us that the tuberculin patch as used at Ealing, contrary to the experience of some others (Deane, 1946), is in general a reliable index of tuberculin sensitivity when this is relatively high.

The ' complete' tuberculin test was attempted in most contact children over the age of one year, and usually in non-contacts when a second attendance could be obtained. Patients not infrequently failed to return for reading of the intradermal test, and sometimes flatly refused to submit to the injection, so that we were left with a record of the patch result only. In spite of this, nearly half of both contacts and non-contacts negative to a patch test subsequently underwent a satisfactory intradermal test. On the perhaps unjustified assumption that these were more likely than not to be positive, we tended to omit altogether tuberculin testing of the older age groups. Such children were x-rayed in the first instance, but in younger children only those tuberculin-positive were $\mathrm{x}$-rayed. The comparative figures are seen in columns 2 and 3 of table 1 .

The 1,050 contacts were distributed fairly evenly by age; of the 426 non-contacts, relatively few were infants, because outside practitioners tended not to refer very young children to the clinic. The number of children patch-tested at each year of age, and the number patch-negative who were subsequently Mantoux-tested, is shown in columns 3 and 6. Column 5 shows the patch-sensitivity rates. In order to compute the complete testsensitivity rates, the observed percentage of Mantoux reactors must be applied to the total patch-negative, as if all patch-negative children, instead of only a sample, had undergone a Mantoux test. This operation gives the adjusted figures shown in column 9. For example, 8.9 of every 100 contacts below the age of one were patch-positive. Of the remaining $91 \cdot 1,30$ per cent. were Mantoux-positive, that is, 27.3. Thus the total percentage reacting 
TABLE 1

TUBERCULIN SENSITIVITY IN 1,476 CHILDREN

\begin{tabular}{|c|c|c|c|c|c|c|c|c|c|}
\hline \multirow{2}{*}{$\begin{array}{l}\text { Age in } \\
\text { years } \\
\text { (1) }\end{array}$} & \multirow{2}{*}{$\begin{array}{c}\begin{array}{c}\text { Total } \\
\text { children }\end{array} \\
\text { (2) }\end{array}$} & \multicolumn{3}{|c|}{ Patch Test } & \multicolumn{4}{|c|}{ Mantoux Test $1: 100$} & \multirow{2}{*}{$\begin{array}{c}\text { Complete } \\
\text { TEST }\end{array}$} \\
\hline & & $\begin{array}{l}\text { Total } \\
\text { (3) }\end{array}$ & $\begin{array}{l}\text { No. } \\
\text { positive } \\
\text { (4) }\end{array}$ & $\begin{array}{l}\text { Per cent. } \\
\text { positive } \\
\text { (5) }\end{array}$ & $\begin{array}{c}\text { Total } \\
\text { (6) }\end{array}$ & $\begin{array}{l}\text { No. } \\
\text { positive } \\
\text { (7) }\end{array}$ & $\begin{array}{l}\text { Per cent. } \\
\text { positive } \\
\text { (8) }\end{array}$ & $\begin{array}{c}\text { Per cent. } \\
\text { positive } \\
\text { (adjusted) } \\
(9)\end{array}$ & \\
\hline $\begin{array}{r}0 \\
1 \\
2 \\
3 \\
4 \\
5 \\
6 \\
7 \\
8 \\
9 \\
10 \\
11 \\
12 \\
13\end{array}$ & $\begin{array}{l}92 \\
80 \\
68 \\
82 \\
73 \\
84 \\
77 \\
74 \\
70 \\
76 \\
55 \\
73 \\
79 \\
67\end{array}$ & $\begin{array}{l}90 \\
78 \\
67 \\
79 \\
69 \\
80 \\
73 \\
70 \\
64 \\
71 \\
47 \\
58 \\
38 \\
10\end{array}$ & $\begin{array}{r}8 \\
15 \\
17 \\
20 \\
22 \\
32 \\
22 \\
30 \\
26 \\
29 \\
17 \\
19 \\
16 \\
3\end{array}$ & $\begin{array}{r}8.9 \\
19 \cdot 3 \\
25 \cdot 4 \\
25 \cdot 3 \\
31.9 \\
40.0 \\
30 \cdot 1 \\
42.9 \\
40 \cdot 6 \\
40 \cdot 8 \\
36 \cdot 2 \\
32 \cdot 8 \\
42 \cdot 1 \\
30.0\end{array}$ & $\begin{array}{c}\text { NTACTS } \\
10 \\
27 \\
21 \\
28 \\
22 \\
24 \\
26 \\
22 \\
21 \\
29 \\
14 \\
22 \\
13 \\
3\end{array}$ & $\begin{array}{r}3 \\
15 \\
12 \\
15 \\
12 \\
17 \\
10 \\
8 \\
9 \\
15 \\
9 \\
11 \\
6 \\
2\end{array}$ & $\begin{array}{l}30 \cdot 0 \\
55 \cdot 6 \\
57 \cdot 1 \\
53 \cdot 5 \\
54 \cdot 5 \\
70 \cdot 8 \\
38 \cdot 9 \\
36 \cdot 4 \\
42 \cdot 9 \\
51 \cdot 7 \\
64 \cdot 3 \\
50 \cdot 0 \\
46 \cdot 2 \\
66 \cdot 7\end{array}$ & $\begin{array}{l}27 \cdot 3 \\
44 \cdot 8 \\
43 \cdot 2 \\
41 \cdot 7 \\
38 \cdot 0 \\
42 \cdot 5 \\
27 \cdot 2 \\
20 \cdot 7 \\
25 \cdot 5 \\
30 \cdot 6 \\
41 \cdot 0 \\
33 \cdot 6 \\
26 \cdot 7 \\
46 \cdot 7\end{array}$ & $\begin{array}{l}36 \cdot 2 \\
64 \cdot 1 \\
68 \cdot 6 \\
65 \cdot 7 \\
69 \cdot 9 \\
82 \cdot 5 \\
57 \cdot 3 \\
63 \cdot 6 \\
66 \cdot 1 \\
71 \cdot 4 \\
77 \cdot 2 \\
66 \cdot 4 \\
68 \cdot 8 \\
76 \cdot 7\end{array}$ \\
\hline Total & 1,050 & 894 & 276 & $30 \cdot 9$ & 282 & 144 & $51 \cdot 1$ & $35 \cdot 3$ & $66 \cdot 2$ \\
\hline $\begin{array}{r}0 \\
1 \\
2 \\
3 \\
4 \\
5 \\
6 \\
7 \\
8 \\
9 \\
10 \\
11 \\
12 \\
13\end{array}$ & $\begin{array}{r}2 \\
8 \\
14 \\
22 \\
21 \\
51 \\
60 \\
37 \\
40 \\
37 \\
24 \\
32 \\
36 \\
42\end{array}$ & $\begin{array}{r}2 \\
8 \\
11 \\
17 \\
18 \\
47 \\
50 \\
30 \\
32 \\
28 \\
18 \\
22 \\
11 \\
14\end{array}$ & $\begin{array}{l}1 \\
0 \\
2 \\
3 \\
0 \\
6 \\
5 \\
7 \\
6 \\
4 \\
3 \\
4 \\
2 \\
6\end{array}$ & $\begin{array}{c}\text { N } \\
50 \cdot 0 \\
0-0 \\
18 \cdot 2 \\
17 \cdot 6 \\
0-0 \\
12 \cdot 8 \\
10-0 \\
23 \cdot 3 \\
18 \cdot 7 \\
14 \cdot 3 \\
16 \cdot 7 \\
18 \cdot 2 \\
18 \cdot 2 \\
42 \cdot 8\end{array}$ & $\begin{array}{c}\text { CONTACT } \\
0 \\
1 \\
2 \\
6 \\
12 \\
18 \\
18 \\
11 \\
9 \\
14 \\
8 \\
11 \\
3 \\
4\end{array}$ & $\begin{array}{l}0 \\
0 \\
1 \\
2 \\
2 \\
3 \\
8 \\
6 \\
4 \\
7 \\
4 \\
7 \\
2 \\
1\end{array}$ & $\begin{array}{r}0-0 \\
0.0 \\
50-0 \\
33 \cdot 3 \\
16 \cdot 7 \\
16 \cdot 7 \\
44.4 \\
54 \cdot 5 \\
44 \cdot 4 \\
50-0 \\
50-0 \\
63.6 \\
66.7 \\
25.0\end{array}$ & $\begin{array}{r}0-0 \\
0-0 \\
40 \cdot 9 \\
24 \cdot 4 \\
16 \cdot 7 \\
13 \cdot 2 \\
39 \cdot 9 \\
41 \cdot 8 \\
37 \cdot 7 \\
42 \cdot 8 \\
41 \cdot 7 \\
52 \cdot 0 \\
54 \cdot 5 \\
14 \cdot 3\end{array}$ & $\begin{array}{r}50 \cdot 0 \\
0.0 \\
59 \cdot 1 \\
42.0 \\
16 \cdot 7 \\
26 \cdot 0 \\
49 \cdot 9 \\
65 \cdot 1 \\
56 \cdot 4 \\
57 \cdot 1 \\
58 \cdot 4 \\
70 \cdot 2 \\
72 \cdot 7 \\
67 \cdot 1\end{array}$ \\
\hline Total & 426 & 308 & 49 & $15 \cdot 9$ & 117 & 47 & $40 \cdot 1$ & $33 \cdot 7$ & $49 \cdot 6$ \\
\hline
\end{tabular}

to tuberculin in this age group is $8 \cdot 9$ plus $27 \cdot 3=36 \cdot 2$, as shown in column 10 .

In the case of contact children, it is clear that a degree of saturation is reached at an early age, after which the proportion of reactors increases but little with each year of age. This is demonstrated histographically in fig. 1, which also shows that much lower figures would have resulted from using the patch test alone.

The total non-contact children, and the proportions tuberculin-tested, were too small to be treated in single year-groups. In fig. 2 they are collected in larger age periods and compared with contact children. The steep rise of positive reactivity in non-contacts is well marked, and again the superiority of the complete test over the patch test is clearly demonstrated.

Tuberculin sensitivity in non-contacts is, as might be expected, less than in contacts at all ages; but it increases much more rapidly with age, to become nearly equal at puberty when the complete test is used-though it still lags if the patch test only is under consideration.

These results agree broadly with those observed in other countries (Brailey, 1940) and with those of Schlesinger and Hart and of Bradshaw in London. There is little to be gained by detailed comparison, for which the reader is referred to Hart (1932), 


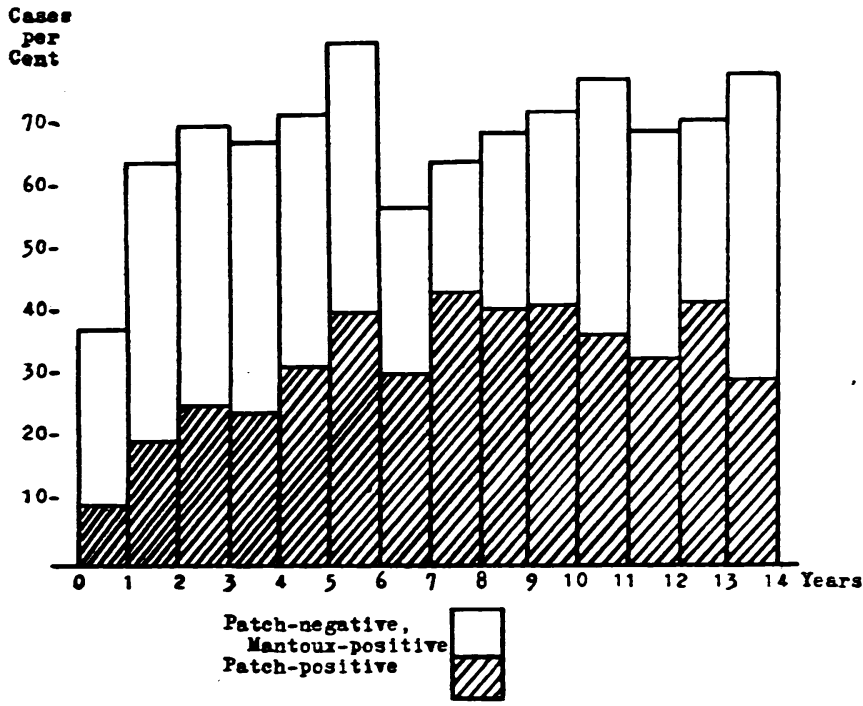

Frg. 1.-Tuberculin sensitivity in 1,050 contacts.

who gives a complete review up to that date. The non-contact children in the present study are not a random population sample; they were all to some extent ill, and were mostly suspected of tuberculosis, though in fact only one in twenty actually proved to be suffering from that disease. That they showed much higher rates of reactivity than Jones Davies's series, for example, may be due to at least three factors: they were urban, as opposed to rural, dwellers; they were presumably ill, not presumably healthy; and they underwent a test more severe than the tuberculin jelly test used in the Welsh survey. The rates found by Heimann and Paterson in presumably healthy urban children (these workers also used tuberculin jelly) were also higher than those of Jones Davies, and correspond quite closely to our results in non-contacts with the patch test alone. This suggests that our sample was perhaps not greatly different from the population at large, especially as Court (1939) has found the patch test to be approximately equal in strength to $1: 1,000$ old tuberculin intradermally, which is also the equivalent strength claimed for tuberculin jelly (Jones Davies, 1943).

Those children who were $\mathrm{x}$-rayed-that is to say, all who were tuberculin positive and all who did not undergo tuberculin test-showed the presence of calcified lesions within the thorax as enumerated in table 2. Calcification occurred as nodules in the lung field, or in the hilar lymph glands, or both. No special radiological technique was employed, such as over-penetration or radioscopy, so that a

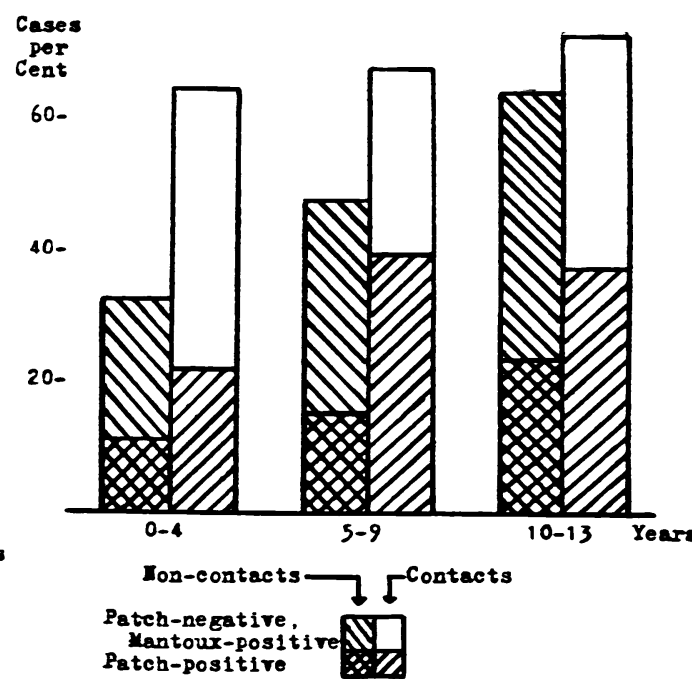

Fig. 2.-Tuberculin sensitivity in 1,050 contacts and 426 non-contacts.

TABLE 2

INCIDENCE OF CALCIFIED LESIONS

\begin{tabular}{|c|c|c|c|c|}
\hline Age in years & $0-4$ & $5-9$ & $10-13$ & Total \\
\hline $\begin{array}{l}\text { Contacts } \\
\text { Non-contacts }\end{array}$ & $\begin{array}{l}9 \\
1\end{array}$ & $\begin{array}{l}34 \\
12\end{array}$ & $\begin{array}{r}40 \\
9\end{array}$ & $\begin{array}{l}83 \\
22\end{array}$ \\
\hline Total & 10 & 46 & 49 & 105 \\
\hline
\end{tabular}

severe standard of interpretation was obligatory and the figures are, therefore, minimal.

\section{Morbidity}

Twenty-three of the 426 non-contacts, and 53 of the 1,050 contact children were found at the time

TABLE 3

CLASSIFICATION OF LESIONS

\begin{tabular}{|c|c|c|c|c|c|}
\hline & \multicolumn{3}{|c|}{ Diagnosed at Clinic } & \multirow{3}{*}{$\begin{array}{l}\text { Diagnosed } \\
\text { elsewhere }\end{array}$} & \multirow{3}{*}{ Total } \\
\hline & \multirow{2}{*}{$\begin{array}{c}\text { Non- } \\
\text { contacts }\end{array}$} & \multicolumn{2}{|c|}{ Contacts } & & \\
\hline & & $\begin{array}{c}1 \mathrm{st} \\
\text { exam. }\end{array}$ & $\begin{array}{r}\text { Re- } \\
\text { exam. }\end{array}$ & & \\
\hline 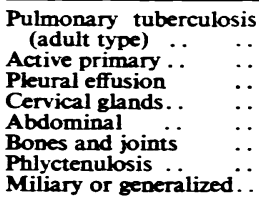 & $\begin{array}{r}2 \\
10 \\
2 \\
6 \\
- \\
3 \\
-\end{array}$ & $\begin{array}{r}2 \\
45 \\
2 \\
2 \\
- \\
1 \\
1\end{array}$ & $\begin{array}{l}\frac{\overline{11}}{1} \\
\overline{-} \\
\overline{1}\end{array}$ & $\begin{array}{r}\overline{17} \\
5 \\
9 \\
3 \\
6 \\
1\end{array}$ & $\begin{array}{r}4 \\
83 \\
9 \\
18 \\
3 \\
6 \\
4 \\
3\end{array}$ \\
\hline Total & 23 & 53 & 13 & 41 & 130 \\
\hline
\end{tabular}


of first examination to have demonstrable tuberculous lesions. Re-examination of initially tuberculin-negative contact children, according to the technique described elsewhere (Thompson, 1944) detected conversion to positive reactivity in 52 cases, of which 13 were accompanied by evidence of gross tuberculosis. During the four-year period under review, in addition to the 89 cases of tuberculosis diagnosed at the clinic, 41 were referred for treatment or observation from outside sources, mainly hospitals, with the diagnosis already established.

The term 'active primary' includes cases of grossly enlarged intrathoracic lymph glands-with or without a distinguishable parenchymal focusand 'epituberculosis,' or cases of lobar or lobular collapse, due to glandular pressure on a bronchus. Of the 66 cases diagnosed at the Clinic, 63 were patch-positive: the other 3 reacted negatively to the patch but positively to the intradermal test. The age distribution of these patients is shown in table 4. The incidence of tuberculous lesions was

TABLE 4

AGE INCIDENCE OF TUBERCULOUS LESIONS

\begin{tabular}{|c|c|c|c|c|c|}
\hline \multirow{3}{*}{$\begin{array}{c}\text { Years of } \\
\text { age }\end{array}$} & \multicolumn{3}{|c|}{ Diagnosed at Clinic } & \multirow{3}{*}{$\begin{array}{l}\text { Diagnosed } \\
\text { elsewhere }\end{array}$} & \multirow{3}{*}{ Total } \\
\hline & \multirow{2}{*}{$\begin{array}{c}\text { Non- } \\
\text { contacts }\end{array}$} & \multicolumn{2}{|c|}{ Contacts } & & \\
\hline & & $\begin{array}{c}\text { 1st } \\
\text { exam. }\end{array}$ & $\begin{array}{c}\text { Re- } \\
\text { exam. }\end{array}$ & & \\
\hline $\begin{array}{c}-1 \\
1-4 \\
5-9 \\
10-13\end{array}$ & $\begin{array}{r}1 \\
3 \\
7 \\
12\end{array}$ & $\begin{array}{r}3 \\
18 \\
24 \\
8\end{array}$ & $\begin{array}{l}3 \\
6 \\
3 \\
1\end{array}$ & $\begin{array}{l}-10 \\
14 \\
17\end{array}$ & $\begin{array}{r}7 \\
37 \\
48 \\
38\end{array}$ \\
\hline Total .. & 23 & 53 & 13 & 41 & 130 \\
\hline
\end{tabular}

approximately equal when averaged for each year of age.

Most of the children with lesions who were clinically ill were admitted to hospitals or sanatoria for treatment. Many of those who remained without symptoms were rested at home and observed as out-patients. With the few exceptions detailed in the following section, complete clinical recovery, with resolution of the lesions - often accompanied by progressive calcification-was the rule.

\section{Mortality}

Death occurred in seven of the children described above. None of the 426 non-contacts died. Of the 41 cases diagnosed outside the clinic as suffering from tuberculosis one case ended fatally - a child with generalized tuberculosis already moribund when notified. The six remaining deaths took place among the 1,050 contacts. All six children
TABLE 5

FATAL CASES DIAGNOSED AT CLINIC

\begin{tabular}{|c|c|c|c|c|c|}
\hline No. & $\begin{array}{c}\text { Age } \\
\text { in } \\
\text { months }\end{array}$ & Sex & $\begin{array}{c}\text { Tuberculin } \\
\text { test }\end{array}$ & $\begin{array}{c}\text { Evidence of } \\
\text { tuberculosis }\end{array}$ & $\begin{array}{l}\text { Survival (in } \\
\text { weeks from } \\
\text { being found } \\
\text { tuberculin- } \\
\text { positive) }\end{array}$ \\
\hline 1 & 7 & $\mathbf{M}$ & Patch + ve & None. X-ray re- & 8 \\
\hline 2 & 7 & $\mathbf{F}$ & $\begin{array}{l}\text { Patch - ve ; } \\
\text { - ve. } 15\end{array}$ & Acute miliary & 2 \\
\hline 3 & 9 & $\mathbf{M}$ & Patch + ve & None. $_{\text {negative }} \mathbf{X}$-ray & 15 \\
\hline $\begin{array}{l}4 \\
5\end{array}$ & $\begin{array}{l}12 \\
13\end{array}$ & $\begin{array}{l}\mathbf{F} \\
\mathbf{F}\end{array}$ & $\begin{array}{l}\text { Patch } \div \text { ve } \\
\text { Patch }- \text { ve } \\
\quad+\text { ve. }\end{array}$ & $\begin{array}{l}\text { Acute miliary } \\
\text { Meningitis }\end{array}$ & 5 \\
\hline 6 & 36 & $\mathbf{F}$ & Patch + ve & $\begin{array}{l}\text { Active primary } \\
\text { complex }\end{array}$ & 7 \\
\hline
\end{tabular}

were in contact with a sputum-positive adult at or near the time of being found tuberculin-positive. The rapidity with which death ensued is in keeping with the observation of Wallgren that fatal generalization from a primary complex occurs almost invariably at about twelve weeks from the development of tuberculin sensitivity. The fact that follow-up of the whole group has not been prolonged, therefore, does not seriously affect the validity of our case-fatality rates. Prolonged illness with a fatal termination (Hurford, 1945) is sufficiently uncommon in childhood tuberculosis to be of relatively little statistical importance.

During the years 1942-45 there were eighteen deaths from tuberculosis (eight males and ten females) in children up to the age of fourteen in the boroughs of Acton and Ealing. Of these nine were known to the clinic before death. Seven have already been described; the other two were known before 1942, and were, therefore, outside the scope of our preliminary study. Of the remaining nine, one was in contact with a known case of tuberculosis, but routine examination had previously been refused. The mother of one was found to have sputumpositive tuberculosis. No source of infection was found in the other seven.

For all ages inclusive in the years 1942-45, deaths from all forms of tuberculosis in Acton and

TABLE 6

TOTAL DEATHS FROM TUBERCULOSIS IN CHILDREN, BOROUGHS OF ACTON AND EALING, 1942-45.

\begin{tabular}{c|c|c|c|c|c|c}
\hline Age in years & -1 & -2 & -5 & -10 & -14 & Total \\
\hline Number of deaths & 4 & 4 & 5 & 3 & 2 & 18 \\
\hline
\end{tabular}


Ealing totalled 450 , an average of 112.5 per annum. Deaths in children were 4.5 per annum, or 4 per cent. of the total. The adult population (about 170,200) had an annual death rate of 63.5 per 100,000 , while the rate for children under fourteen (about 41.800 ) was 10-2.

\section{Discrassion}

These figures should help us to examine tuberculosis in childhood both as a separate problem and in relation to tuberculosis as a whole. It seems that the population under review, even though the groups subjected to tuberculin test are not true samples, incurs a heavy rate of infection with the tubercle bacillus at an early age, and that this rate has a rapid annual increase. In spite of this, the deaths occurring during childhood from tuberculosis-which are by no means confined to the years of early infancy-are very few, both in absolute numbers and in comparison with deaths from other causes. Healed tuberculous lesions, with radiological evidence of calcification, are encountered at all ages. A large proportion of children show a low degree of sensitivity to tuberculin, being negative to the patch test but positive to a strong intradermal injection, which may be presumed to indicate a tuberculous infection becoming obsolete.

It would seem, therefore, that children in this district are able to resist tuberculous infection remarkably well. Even of those with massive intrathoracic lesions, only 1 in 83 failed to make an initial recovery, with or without institutional treatment. In this connexion, it is well to remember that there is nowhere in the literature any statistical evidence that sanatorium treatment and its ancillary methods have any influence on the fate of the primary complex, and Myers (1944) even advances positive evidence to this effect. One would not, however, deny the value of individual clinical observations (Roberts, 1943; Richards, 1944).

This does not mean that tuberculosis in childhood is negligible. Our material takes no account of residual illness from resolved primary lesionssuch as bronchiectasis or peritoneal adhesions-or of the occasional case of late haematogenous dissemination. Nor can it help us to forecast the type of case that may develop pulmonary tuberculosis in adult life. The work of Israel and de Lien (1942) suggests that such a development depends less on the character of the primary infection than on the maintenance of contact with an infective source up to and during adolescence. In diagnosing large numbers of adults with pulmonary tuberculosis, it is remarkable how rarely one finds a history of tuberculosis in childhood. On the other hand, those adults actually in contact with infectious tuberculosis, and who themselves develop tuberculous lesions, do so, with very few exceptions (Thompson, 1944), either while still in contact or within eighteen months of the cessation of contact. Despite the allegiance of such authorities as Moncrieff (1945) to the continental view of endogenously-derived phthisis, we are constantly impressed by the important part played by immediate external infection in adult life. We do not, however, allow this to divert us from the task of breaking contact between children and an infectious source, preferably by isolation or by treatment of the infected patient, otherwise by boarding out the children under the usual Local Authority arrangements. We are extremely reluctant to segregate young children in institutions, as is sometimes advocated (Carling, 1946). Such a policy would be uneconomical in view of the large numbers and the necessarily prolonged periods of stay involved. Moreover, it is fundamentally undesirable for social and psychological reasons. The experience at Lymanhurst (Myers, 1944) suggests that the " preventorium 'system has no discernible effect on mortality from primary tuberculous infection. Our figures indicate that this mortality is in any case small, and that the fatal cases are so fulminating that any known treatment is useless.

It scems probable that children who are sick are usually, though not always, better off in hospital. Children with sub-clinical lesions may be hospitalized if home conditions are poor, but a good home and a good mother may be preferable if no special treatment is indicated, especially if the child is under school age. In children who are tuberculinnegative, infection must be prevented at all cost, or forestalled by B.C.G. inoculation or its equivalent, though the latter is in our opinion a poor compromise, abounding with administrative difficulties. When a child is already infected, tuberculin-positive, but clinically not ill and without a demonstrable lesion, it is the practice to break contact with the infectious source just as if infection had not already occurred. This is on the assumption that repeated infection carries an increased danger, an assumption that is constantly reiterated in textbooks (Miller and Wallgren, 1939), although it has never been proved, and is contrary to most experimental work. The child's reaction to a primary tuberculous infection is in several respects different from the adult's, and children may thus react differently to repeated, as opposed to a single, exposure. More factual information is required before the thesis can be accepted that re-infection is an additional 
menace to children; the assumption of the thesis as a practical safeguard is meanwhile justifiable.

\section{Conchusions}

In the absence of large-scale tuberculin testing of true population samples, selected groups studied at the Ealing Chest Clinic give some guide to the incidence of tuberculous infection at different ages in childhood for the population concerned. The patch test has proved a reliable index of a relatively high degree of sensitivity to tuberculin. Results of epidemiological value, however, require the use of intradermal tests equal to at least $1 / 100$ old tuberculin in children negative to the patch test. The patch test alone will detect sensitivity in most cases of active tuberculosis with manifest lesions. Routine examination of children known to have been in contact with tuberculosis will reveal active tuberculosis in a proportion at least as high as that found in children who are not known contacts but who have symptoms. The highest incidence of manifest lesions is found in children at the time of conversion from a negative to a positive tuberculin reaction. Negative reactors should, therefore, be repeatedly re-tested so long as the risk of infection continues.

The immediate prognosis of tuberculous primary infection in childhood, with or without a demonstrable lesion, is, from the statistical point of view, good. The mortality rate among patients attending the clinic was exceedingly small. Those children who died, did so within three or four months; in general there was no early indication that might aid prognosis. Of the total deaths from tuberculosis in children, the majority occurred suddenly, in the absence of a history of contact or of prolonged illness. It, therefore, does not appear that medical treatment can be expected to influence the outcome in children with primary tuberculous infection, or that the detection of a higher proportion of such cases by intensified diagnosis is likely to diminish the general mortality. We cannot say whether any given child will or will not undergo a rapid and fatal generalization of the disease, nor probably have we at present power to influence the issue. We can predict with some confidence a more or less complete recovery if the first three months are survived. Beyond that we can only speculate. The proportion of surviving children who will later develop haematogenous lesions in bone or kidney is probably very small indeed. Those who will develop phthisis after adolescence are more likely to do so by reason of continued or resumed contact with an outside source of tuberculous infection during that later period, than because of the character of their primary infection. The cleaning out of infectious tuberculosis from each household, therefore, becomes a paramount object.

For these reasons it would seem that the mortality from tuberculosis in childhood can be substantially reduced only by discovering and eliminating infectious tuberculosis in adults, and our energies should be concentrated to this end.

\section{Summary}

A study is presented of all children examined at the Ealing Chest Clinic during four successive years, in relation to the total mortality from tuberculosis in children in the district during the same period.

The incidence of sensitivity to patch and intradermal tuberculin tests, of calcified lesions, and of active manifest tuberculosis, is compared in children who were, and children who were not, known to have been in contact with tuberculosis.

A policy is sought for rationalizing the control of primary tuberculous infection and disease in children.

\section{REFERENCES}

Bradshaw, D. B. (1939). Brit. med. J., 1, 825.

Brailey, M. (1940). Amer. J. Hyg., 31, 1.

Carling, E. (1946). Brit. med. J., 1, 412.

Court, D. (1939). Ibid., p. 824.

Deane, E. H. W. (1946). Lancet, 1, 162.

Dow, D. J., and Lloyd, W. E. (1931). Brit. med. J., 2, 183.

Hart, P. D. (1932). M.R.C. Spec. Rep. No. 164. London.

Heimann, F. A., and Paterson, H. R. (1945). Med. Off., 74, 209.

Hurford, J. V. (1945). Lancet, $2,624$.

Israel, H. L., and de Lien, H. (1942). Amer. J. Publ. Hlth., 32, 1146.

Jones Davies, T. E. (1943). 'A Study of the Incidence and Epidemiology of Tuberculous Infection in the Elementary School Population of the County of Radnor.' Publ. Hlth. Rep., Radnor, Wales.

Miller, J. A., and Wallgren, A. (1939). Pulmonary Tuberculosis in Adults and Children. New York.

Moncrieff, A. (1945). Lancet, 2, 621.

Myers, J. A. (1944). The Evolution of Tuberculosis as Observed During Twenty Years at Lymanhurst, Minneapolis, Minn., 1921 to 1941 . Minneapolis.

Richards, W. F. (1944). Tubercle, 25, 60.

Roberts, J. C. (1943). Lancet, $2,2$.

Schlesinger, B., and Hart, P. D. (1930). Arch. Dis. Childh., 5, 191.

Thompson, B. C. (1944). Publ. Hlth., 57, 111. 